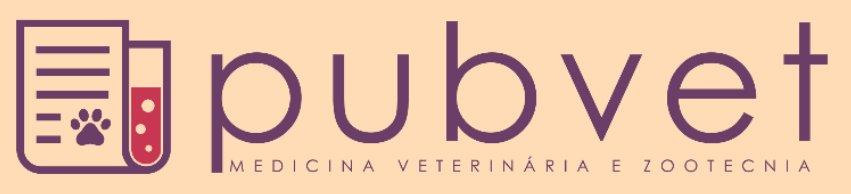

https://doi.org/10.31533/pubvet.v15n05a801.1-5

\title{
Reconstrução dermo-facial de canino com avulsão de lábio superior bilateral: Relato de caso
}

\author{
Rainer da Silva Reinstein ${ }^{*} \bullet$, Lucas Werle $\operatorname{Vogel}^{2} \bullet$, Emanuelle Bortolotto Degregori ${ }^{1} \bullet$,

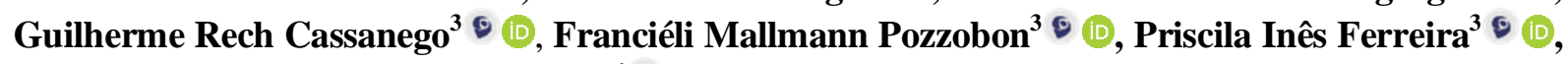 \\ Daniel Curvello de Mendonça Müller ${ }^{4} \theta$ \\ ${ }^{1}$ Aluno da Universidade Federal de Santa Maria, Programa de Pós-graduação em Medicina Veterinária. Santa Maria-RS Brasil. \\ ${ }^{2}$ Médico Veterinário Autônomo, Especialista em Clínica Cirúrgica de Pequenos Animais. \\ ${ }^{3}$ Aluno da Universidade Federal de Santa Maria, Curso de Graduação em Medicina Veterinária, Santa Maria-RS Brasil. \\ ${ }^{4}$ Professor Adjunto da Universidade Federal de Santa Maria, Departamento de Clínica de Pequenos Animais. Santa Maria-RS Brasil. \\ *Autor para correspondência, E-mail: rainerreinstein@gmail.com
}

Resumo. A cirurgia reconstrutiva, utiliza-se da redistribuição tecidual, para o tratamento de defeitos traumáticos de pele, quando fechamento primário não é possível. Resultam em redução de infecções, além de facilitar sobremaneira o manejo da ferida. Traumatismos faciais em cães, principalmente no focinho, cursam com pouca pele adjacente, o que torna a cirurgia reparadora um desafio cirúrgico. Desta forma, este trabalho, relata o caso de um cão atendido no Hospital Veterinário Universitário da Universidade Federal de Santa Maria (HVU-UFSM), apresentando lesão bilateral em lábio superior e plano nasal, com perda considerável de tecido, mas que culminou com bons resultados estéticos e funcionais após cirurgias reparadoras.

Palavras-chave: Cirurgia reconstrutiva, veterinária, plano nasal

\section{Dermo-facial reconstruction of a canine with bilateral upper lip avulsion: Case report}

\begin{abstract}
Reconstructive surgery uses tissue redistribution to treat traumatic skin defects, when primary closure is not possible. They result in reduced infections, in addition to greatly facilitating the management of the wound. Facial injuries in dogs, mainly in the muzzle, have little adjacent skin, which makes restorative surgery a surgical challenge. Thus, this work reports the case of a dog seen at the Veterinary University Hospital of the Federal University of Santa Maria (HVU-UFSM), presenting bilateral lesion in the upper lip and nasal plane, with considerable loss of tissue, but which culminated in good aesthetic and functional results after reparative surgery.
\end{abstract}

Keywords: Reconstructive surgery, veterinary, nasal plane

\section{Reconstrucción dermo-facial de un canino con avulsión bilateral del labio superior: Reporte de caso}

Resumen. La cirugía reconstructiva utiliza la redistribución de tejidos para tratar defectos cutáneos traumáticos, cuando no es posible el cierre primario. Dan como resultado una reducción de las infecciones, además de facilitar mucho el manejo de la herida. Las lesiones faciales en perros, principalmente en el hocico, tienen poca piel adyacente, lo que hace que la cirugía reparadora sea un desafío quirúrgico. Así, este trabajo reporta el caso de un perro atendido en el Hospital Universitario Veterinario de la Universidad Federal de Santa María 
(HVU-UFSM), que presenta lesión bilateral en labio superior y plano nasal, con considerable pérdida de tejido, pero que culminó en buena Resultados estéticos y funcionales tras la cirugía reparadora.

Palabras clave: Cirugía reconstructiva, veterinaria, plano nasal

\section{Introdução}

A cicatrização de ferimentos é um processo biológico que restaura a continuidade do tecido após lesionado. É uma combinação de eventos físicos, químicos e celulares que restauram o tecido ferido ou o substituem por colágeno, e começa imediatamente após a lesão ou incisão (Fossum, 2014). A designação de ferida diz respeito a uma solução de continuidade na superfície externa do corpo ou na superfície de um órgão interno (White, 1999), ou seja, a ruptura ou perda da continuidade celular ou anatômica. Traumatismos estão frequentemente associados a esta definição, sendo aplicada a lesões físicas ou feridas com origem em forças externas ou violentas com energia de impacto não tolerável pelos tecidos atingidos (Pavletic, 2018).

Várias são as técnicas de reconstrução tecidual, portanto no momento da escolha da técnica a ser utilizada, deve-se levar em conta localização da ferida, tamanho, linhas de tensão, disponibilidade de pele e, principalmente, a preferência e experiência do cirurgião quanto à técnica a ser utilizada (Fossum, 2014; Slatter, 2007). Cirurgias reconstrutivas do lábio superior são importantes por restaurar a função da cavidade oral e alcançar um resultado estético satisfatório (Pavletic, 2018). Segundo Fossum (2014), a face dos cães é uma região naturalmente susceptível a lesões externas pelo seu hábito de farejar e morder. Defeitos na face podem ser de difícil resolução, principalmente por essa região estar ao alcance das patas e passíveis de trauma no período pós-operatório (Pavletic, 2018).

A literatura dispõe de várias formas de tratamento; porém, caso os princípios básicos da cirurgia reconstrutiva não sejam observados, a probabilidade de fracasso na terapia deve ser considerada. Logo, objetiva-se descrever o caso de reconstrução dermo-facial de um cão com avulsão de lábio superior bilateral e plano nasal que obteve bons resultados após tratamento inicial sem sucesso.

\section{Relato de caso}

Foi atendido no Hospital Veterinário Universitário (HVU) da Universidade Federal de Santa Maria (UFSM) um canino, macho, com 10 anos de idade, $14,5 \mathrm{~kg}$ e sem raça definida. O cão foi encaminhado apresentando histórico de avulsão bilateral de lábio superior e plano nasal, após sofrer trauma ao ficar preso em uma grade metálica. Recebeu como tratamento prévio ao atendimento, cirurgia reparadora com retalho de avanço direcional. Durante o período pós-operatório o paciente arrancou os pontos com as patas, permanecendo com a ferida aberta por 10 dias (Figura 1).

Após exame físico e clínico optou-se pela internação do animal, permitindo alimentação por sonda de faringostomia e tratamento farmacológico de apoio. Os debris celulares foram retirados e a ferida foi limpa duas vezes ao dia, seguida de utilização de açúcar cristal, visando a formação de leito de granulação saudável. Após 10 dias de tratamento das lesões o paciente foi encaminhado para cirurgia.

Respeitado o jejum hídrico de seis horas e alimentar de oito horas, promoveu-se indução à anestesia geral com diazepam $(0,3 \mathrm{mg} / \mathrm{kg})$, cloridrato de cetamina $(1 \mathrm{mg} / \mathrm{kg})$ e propofol $(4 \mathrm{mg} / \mathrm{kg})$, todos por via intravenosa (IV). Além disso, a anestesia local foi realizada com cloridrato de bupivacaína $(0,25 \mathrm{mg} / \mathrm{kg})$ e utilizado citrato de fentanila $(5 \mu \mathrm{g} / \mathrm{kg} / \mathrm{h})$ e cloridrato de cetamina $(10 \mu \mathrm{g} / \mathrm{kg} / \mathrm{min})$ em infusão contínua para analgesia. A manutenção da anestesia foi realizada com isofluorano, vaporizado em gás oxigênio a $100 \%$ em circuito semifechado.

Introduziu-se uma sonda uretral $\mathrm{n}^{\circ} 10$ em cada narina, visando permitir o fluxo de ar no pósoperatório, além de evitar o colabamento nasal. Aplicado dois pontos de reparo em cada lateral dos lábios, realizou-se incisão paralela ao plano nasal bilateral, confeccionando duplo retalho unipediculado, incluindo as artérias e veias labiais superiores (Figura 2).

Foi realizada síntese da mucosa labial com a oral com fio PDX $\mathrm{n}^{\circ} 3-0 \mathrm{em}$ pontos isolados, ocluindo possível galeria que permitisse acúmulo futuro de alimento. As bordas foram mantidas em aposição na região labial com fio $\mathrm{PDX} \mathrm{n}^{\circ}$ 3-0. Logo após a região dorso nasal foi divulsionada, com aproximação do subcutâneo 
no plano nasal com mesmo tipo de fio. Ao final, realizou-se incisão de relaxamento ventral a incisão lateral, a fim de reorganizar o tecido. Realizada a síntese de toda a porção mucosa, procedeu-se a sutura da pele, com fio de náilon n³-0 no padrão isolado simples. O tratamento pós-operatório compreendeu a manutenção da sonda de faringostomia para alimentação, analgesia, anti-inflamatório, antimicrobiano, colar protetor e limpeza no local das incisões com gaze e solução de $\mathrm{NaCl} 0,9 \%$.

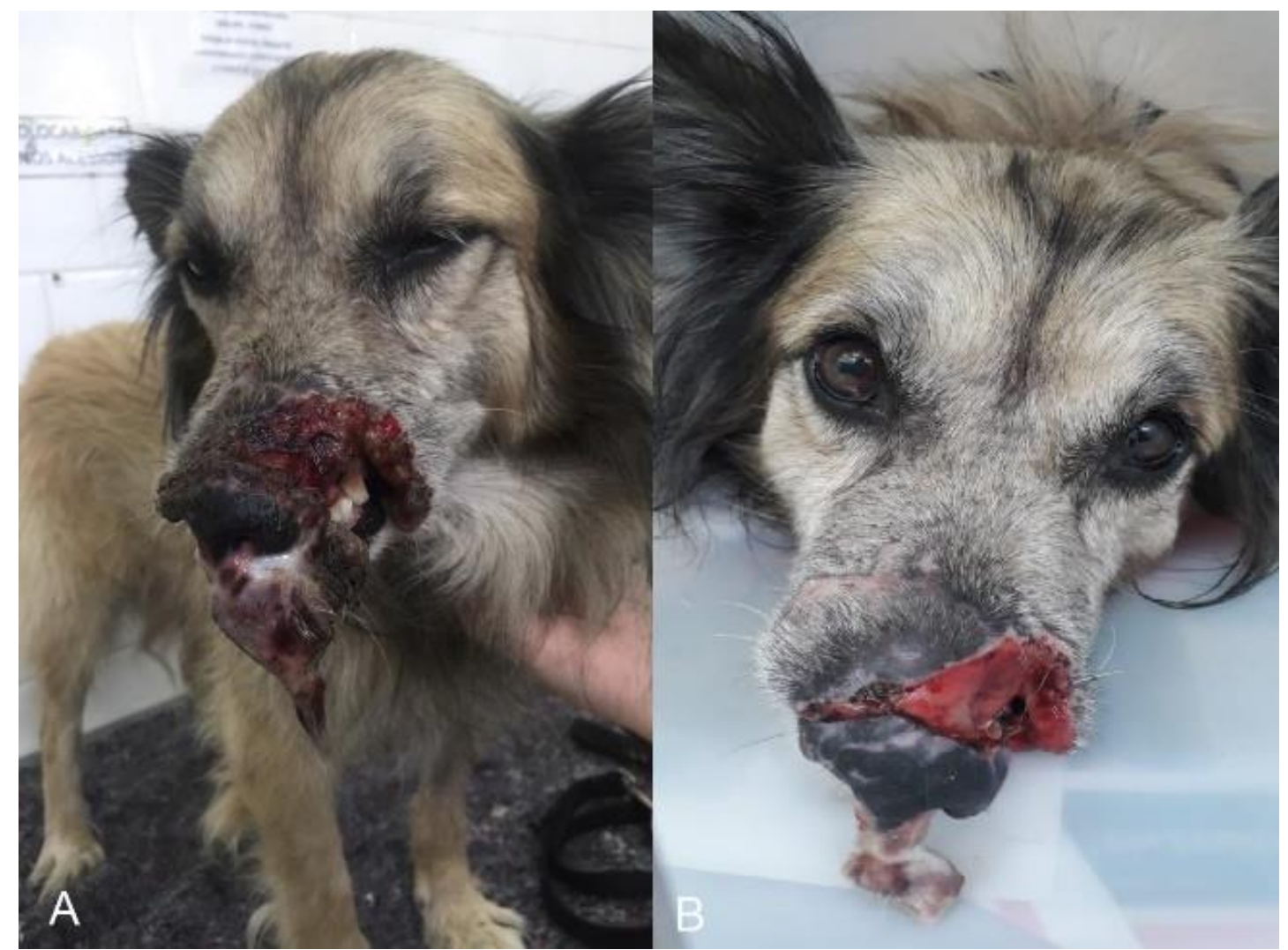

Figura 1. (A) Paciente no $1^{\circ}$ dia de internação, observar ferida com sujidades e áreas desvitalizadas. (B) Paciente no $6^{\circ}$ dia de internação, observar início de leito de granulação saudável na área da ferida.

O paciente permaneceu internado por mais nove dias, sendo que no $6^{\circ}$ dia pós-operatório procedeuse a retirada da sonda de faringostomia, sendo ofertada alimentação pastosa. Ao $9^{\circ}$ dia foram retirados os pontos cirúrgicos e o paciente recebeu alta hospitalar.

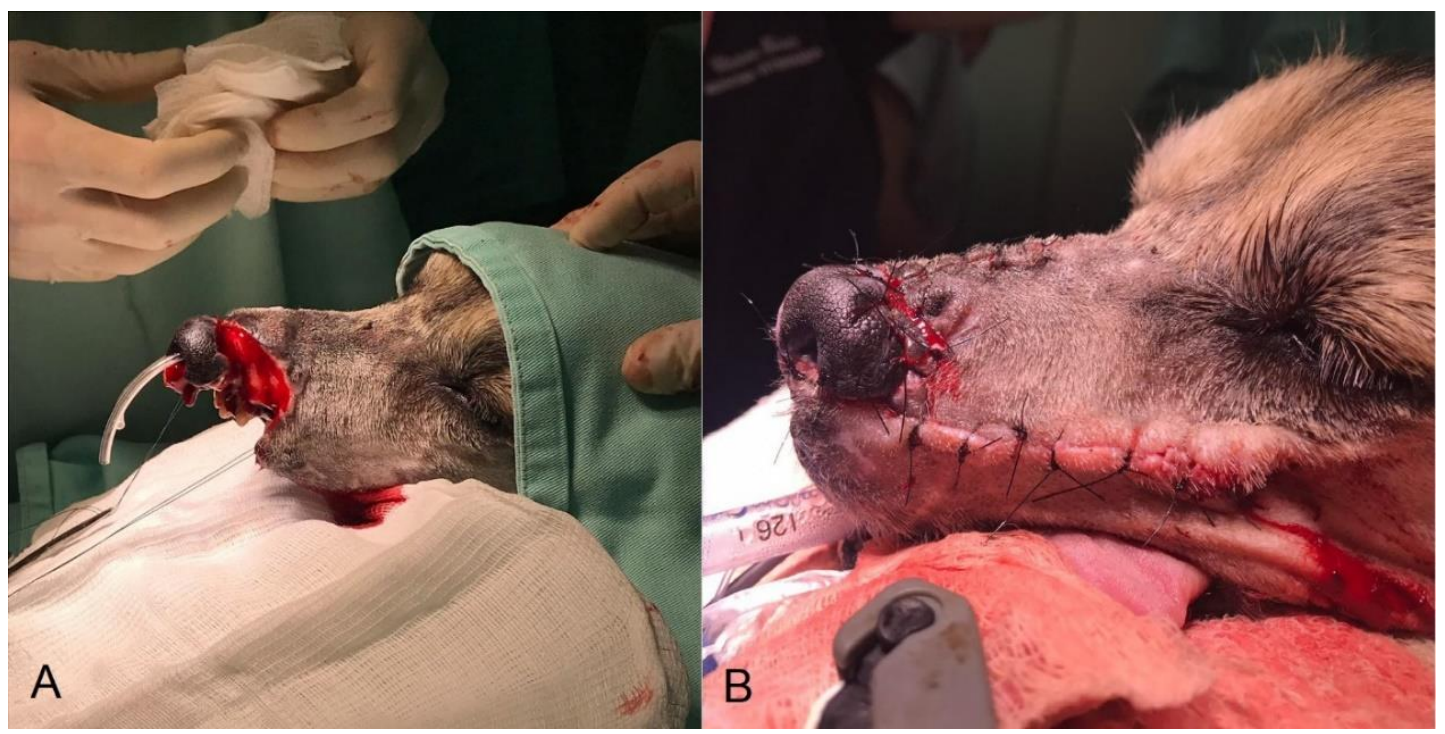

Figura 2. (A) Introdução de sonda de uretral $\mathrm{n}^{\circ} 10 \mathrm{em}$ cada narina e aplicação de dois pontos de reparo em cada lateral dos lábios. (B) Paciente ao término do primeiro procedimento cirúrgico. 
Em acompanhamento pós-cirúrgico do paciente, 10 dias após alta hospitalar, notou-se estenose da narina direita e formação de fístula oronasal, sendo encaminhado para correção cirurgica (Figura 3). Foi realizada incisão horizontal bilateral no plano nasal ventral, possibilitando a elevação da narina e a oclusão da fístula oronasal. Para oclusão foi utilizado fio mononáilon $n^{\circ}$ 3-0 em sutura padrão colchoeiro em cruz. A síntese da narina teve início pela rafe nasal, proporcionando reposicioná-la com a porção central dos lábios, após foi realizada a síntese do plano ventral da narina. Por fim, para tratar a estenose nasal, uma rinoplastia foi realizada, sendo retirado bilateralmente uma cunha da cartilagem alar, e sutura isolada simples com fio de náilon. Após 10 meses dos procedimentos cirúrgicos foi realizado contato telefônico com a tutora, que relatou ótima recuperação do animal, sem dificuldades respiratórias e excelente resultado estético.

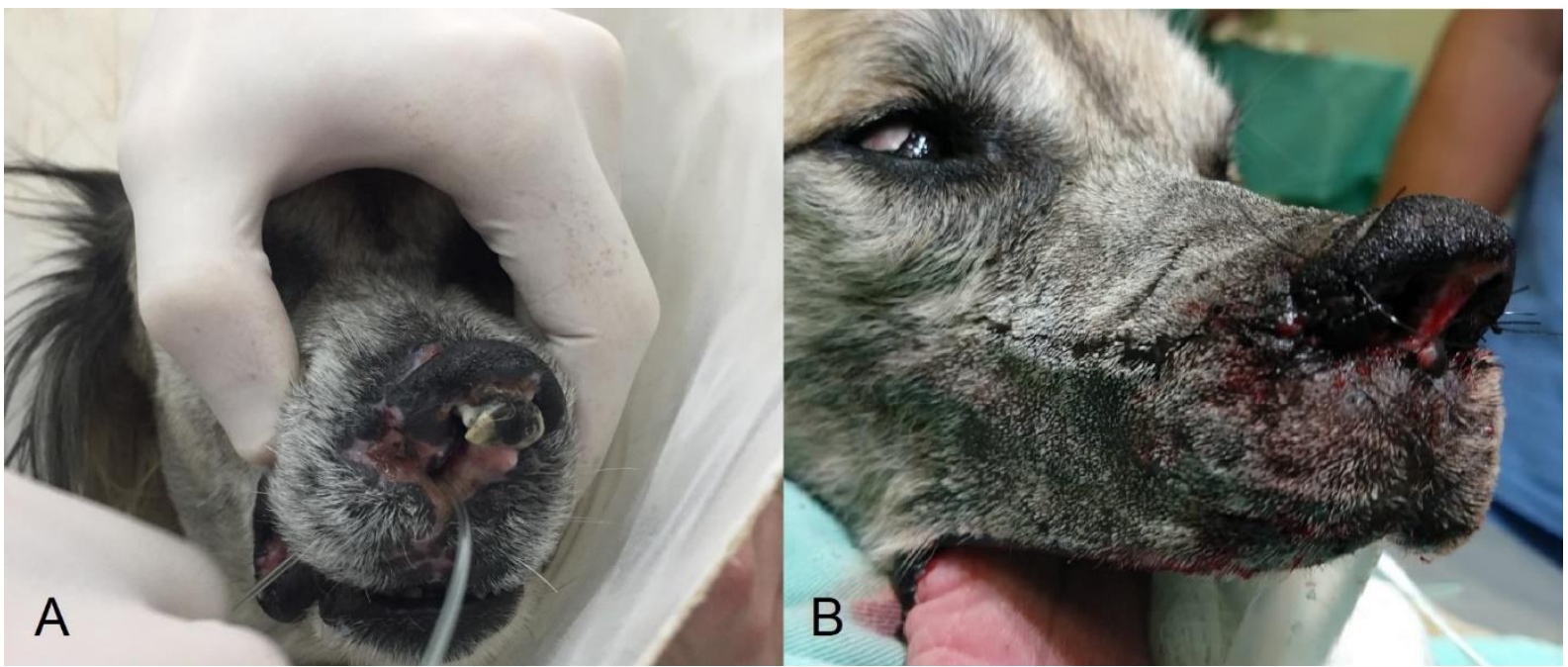

Figura 3. (A) Estenose da narina direita e formação de fístula oronasal. (B) Paciente ao término do segundo procedimento cirúrgico.

\section{Discussão}

A cirurgia reconstrutiva, refere-se à utilização de técnicas de reconstrução tecidual, como retalhos cutâneos e enxertos, na correção de defeitos traumáticos de pele, quando fechamento primário não é possível devido a tensão tecidual (Coltro et al., 2011; Fossum, 2014; Slatter, 2007). A ferida por avulsão corresponde a violenta separação dos tecidos, normalmente com envolvimento de tecido muscular. Estas lesões podem ser completas, quando há remoção em espessura total de fragmento de tecido ou parciais, quando não ocorre total desunião do tecido (Pavletic, 2018; Pope, 2009).

O insucesso na primeira tentativa de tratamento condiz com o relato de Friend (2009), o qual cita o traumatismo infligido pelo próprio paciente como uma das causas mais frequentes de complicações em cirurgia reconstrutiva, decorrendo em deiscência e, por consequência, infecção da lesão. Complicação esta não observada durante o período de internação no HVU em função do uso de colar elizabetano e monitoração constante.

Uma avaliação adequada da ferida deve ser realizada objetivando o plano de tratamento. Dernell (2006) and Schossler (2013) recomendam como medida inicial, tricotomia e limpeza da área atingida, sendo indicado utilização de solução fisiológica estéril para a lavagem e esta deve ser realizada de maneira exaustiva. A realização do desbridamento e utilização de açúcar cristal para tratamento da ferida são técnicas amplamente citadas na literatura (Dernell, 2006; Fossum, 2014; Schossler, 2013). Segundo Dernell (2006), o desbridamento é sempre indicado, pois permite a remoção de tecido necrótico e detritos que não tenham sido removidos na lavagem inicial.

Pavletic (2018) relata que a avulsão de lábio superior é menos comum que as lesões de avulsão de lábio inferior. Como tratamento, indica o retalho de avanço labial em sua totalidade, incluindo a artéria e veia labial superior. Isso permite suprimento sanguíneo adequado, o que converge com a técnica de reconstrução escolhida para o paciente.

A distorção observada no plano nasal é passível de ocorrer, desencadeada pela retração elástica do tecido (Pavletic, 2018), podendo ser a causa da estenose da narina. A fístula oro nasal ocorreu por falha 
na cicatrização, e quando ocorre, sua oclusão deve ser realizada com tecido adjacente e flap gengival (Schossler, 2013). Conforme Mazzaro \& Leon-Roman (2016), a estenose de narina é o estreitamento do orifício nasal, que fica reduzido a uma fenda, dificultando a respiração. A rinoplastia é o tratamento de eleição para esses pacientes, considerada de fácil realização, possibilitando bom prognóstico no restabelecimento da respiração. Acredita-se que o sucesso do tratamento se deve à atenção aos princípios básicos de cirurgia reconstrutiva, com aplicação de conhecimento técnico, assepsia rigorosa, mínima manipulação dos tecidos, redução de espaço morto, respeito à máxima tensão da pele e garantia de leito sanguíneo (Pavletic, 2018), evitando-se assim as principais complicações: hematomas, seromas, deiscência, infeção e edema (Friend, 2009), garantindo ao paciente o retorno das funções mastigatórias e respiratórias, com ótima aparência estética.

\section{Conclusão}

A utilização de retalhos de avanço unidirecional na região facial, são adequados para lesões próximas ao plano nasal, proporcionando cicatrização das lesões cutâneas, com retorno estético e funcional da cavidade oral.

\section{Referências}

Coltro, P. S., Ferreira, M. C., Batista, B. P. S. N., Nakamoto, H. A., Milcheski, D. A., \& Tuma Júnior, P. (2011). Atuação da cirurgia plástica no tratamento de feridas complexas. Revista do Colégio Brasileiro de Cirurgiões, 38(6), 381-386. https://doi.org/10.1590/s0100-69912011000600003.

Dernell, W. S. (2006). Initial wound management. Veterinary Clinics: Small Animal Practice, 36(4), 713-738. https://doi.org/10.1016/j.cvsm.2006.04.003.

Fossum, T. W. (2014). Cirurgia de pequenos animais (4th ed., Vol. 1). Elsevier Brasil.

Friend, E. (2009). Complications of wound healing. In J. Williams \& A. Moores (Eds.), BSAVA Manual of canine and feline wound management and reconstruction. British Small Animal Veterinary Association.

Mazzaro, L., \& Leon-Roman, M. A. (2016). Correção de estenose de narina-Relato de caso. Revista de Educação Continuada em Medicina Veterinária e Zootecnia do CRMV-SP, 14(2), 55.

Pavletic, M. M. (2018). Atlas of small animal wound management and reconstructive surgery (WileyBlackwell (ed.)). John Wiley \& Sons.

Pope, J. (2009). Wound aetiology and classification. In J. Williams \& A. Moores (Eds.), BSAVA Manual of canine and feline wound management and reconstruction. British Small Animal Veterinary Association.

Schossler, J. E. W. (2013). Conceitos básicos de clínica cirúrgica veterinária. In Santa Maria: Editora da UFSM. Universidade Federal de Santa Maria, Rio Grande do Sul.

Slatter, D. H. (2007). Manual de cirurgia de pequenos animais (Vol. 2). Manole São Paulo.

White, R. A. (1999). The etiology and classification of wounds and skin deficits. In D. Fowler \& J. M. Williams (Eds.), BSAVA Manual of canine and feline wound management and reconstruction. British Small Animal Veterinary Association.

\section{Histórico do artigo:}

Recebido: 17 de novembro de 2020 Aceito: 14 de dezembro de 2020

Disponível online: 30 de março de 2021.
Licenciamento: Este artigo é publicado na modalidade Acesso Aberto sob a licença Creative Commons Atribuição 4.0 (CC-BY 4.0), a qual permite uso irrestrito, distribuição, reprodução em qualquer meio, desde que o autor e a fonte sejam devidamente creditados. 